\title{
A SOCIEDADE CIVIL E A LUTA CONTRA A FOME NO BRASIL (1993-2003)
}

\section{Céli Regina Jardim Pinto*}

\begin{abstract}
Resumo: O presente artigo tem como propósito central examinar um conjunto de ações de organizações da sociedade civil brasileira no sentido de dar conta da questão da fome no Brasil. Está dividido em duas partes. A primeira discutirá brevemente a questão social no país a partir de duas assertivas: o Brasil é um país economicista e garante constitucionalmente direitos sociais sem, no entanto, garantir políticas sociais. Na segunda parte do artigo será examinado um conjunto de ONGs que desenvolveram na década de 1990 projetos de combate a fome no Brasil. A análise partirá de duas hipóteses: 1) o problema da fome tende a ser isolado de uma contextualização estrutural; 2) as ONGs, ao tomarem para si a tarefa de resolver a questão, passam a se auto constituírem como sociedade civil e a se relacionarem com as populações excluídas de forma hierárquica.
\end{abstract}

Palavras-chave: sociedade civil, terceiro setor, ONGs, voluntarismo, direitos sociais

O conjunto de dados apresentados e analisados neste artigo faz parte de um projeto com ambições mais amplas, que vem estudando os espaços ocupados por organizações não-governamentais (ONGs) nas últimas duas décadas no Brasil, principalmente no que concerne à sua relação com o Estado. Esta relação pode ser examinada a partir de duas perspectivas das ONGs: como "representantes" da sociedade civil frente ao Estado; e, como "tomando o lugar" do Estado frente à sociedade. As ONGs do primeiro tipo são aquelas que estão nos conselhos gestores, em

* Doutora em Ciência Política pela Universidade de Essex, Inglaterra; professora do Departamento de Ciência Política da Universidade Federal do Rio Grande do Sul (UFRGS).

Artigo recebido em 9 fev. 2005; aprovado em 2 mar. 2005. 
assessorias governamentais, que executam ações de accountability e lobby junto aos poderes do Estado (Pinto, 2004).

A segunda forma de relacionamento, isto é, quando as ONGs apresentam-se à sociedade no lugar do Estado, entre as quais se encontram as que serão analisadas a seguir, merecem neste momento um pouco mais de atenção, pois abrigam pelo menos dois tipos distintos de organização as ONGs, a maioria de pequeno e médio porte, que surgem no espectro público, como formuladoras e proponentes de ações e campanhas dirigidas às populações carentes ou em condição de risco; e as organizações ligadas a grandes empresas, muitas vezes constituindo-se em fundações, que fazem ações que estariam sob o guarda-chuva do que se convencionou chamar de Terceiro Setor.

Apesar de em ambos os tipos de organização poder haver transferência de recursos e tarefas, é nas ações do Terceiro Setor que a ideologia de que a transferência resulta em mais eficiência e melhores ganhos para a população está mais fixada. No primeiro tipo a justificativa da ação está mais próxima de tomar uma posição devido à omissão do Estado, e não devido à possibilidade de fazer melhor do que o Estado faria.

Tomando um conjunto de ações contra a fome levadas a efeito por ONGs comprometidas com a questão social, seja por razões ideológicas, religiosas ou por pura solidariedade, durante uma década, a hipótese que este artigo pretende perseguir diz respeito às possibilidades e limites destas ações, e é a seguinte: as ONGs são organizações com limitações fundantes para levar a cabo com êxito, as missões de substituir o Estado em ações dirigidas a populações carentes ou em situação de risco e três destas limitações fundamentais são: a não obrigação da universalidade; a dependência de recursos; o voluntariado.

\section{Nota introdutória sobre a questão social no Brasil}

O Brasil experimentou, durante o século XX, pelo menos dois momentos de grandes avanços em termos de conquistas de direitos: o primeiro deles em plena ditadura Estadonovista, nos ano de 1940, 
quando Vargas promulgou a Consolidação das Leis Trabalhistas; o segundo em 1988, quando, após uma longa e negociada transição para a democracia, o Congresso Nacional Constituinte promulgou a nova Constituição do país. Em ambos os momentos, não há dúvidas, houve ganhos para a população, em geral, e para as camadas mais pobres, em particular; mas, deve-se ter presente que tal fato aconteceu muito mais por uma complexa dinâmica dos momentos, do que por políticas sociais focadas nas necessidades das populações e na vontade de os governos fazerem valer os direitos assegurados em sofisticados sistemas legais.

Certamente, as condições de vida da população brasileira mudaram, e muito. Ao longo do século XX, houve um grande aumento da riqueza no País, que deixou de ser agrário e passou ser industrial, tornou-se urbano, aumentou a expectativa de vida, seus níveis de educação formal, etc. A partir da Constituição de 1988, a população teve assegurado atendimento universal à saúde, entre outros importantes direitos. Mas nenhum destes direitos foi suficiente para engendrar, no interior do Estado, ações capazes de mudar a feição da exclusão no País. Frente a este quadro, a questão central que emerge é a da quase ausência de políticas sociais específicas capazes de criar condições para que a população mais pobre e excluída tenha acesso aos direitos assegurados legalmente, ou, em outros termos, tenha acesso à cidadania.

Neste quadro, o País tem mantido, historicamente, parte significativa de sua população abaixo do nível da pobreza, em situação, portanto, de fome. Se, na segunda metade do século XX, o País experimentou períodos de grande crescimento econômico, isto não resultou em uma transformação na condição das parcelas mais pobres da população. Diferentes governos, diferentes ideologias compartilharam um menosprezo por políticas sociais focadas nestes segmentos. O populismo da década de 50 e o período de autoritarismo dos governos militares dividiram a crença de que a solução da pobreza seria decorrência do desenvolvimento econômico. A posição mais à esquerda sempre entendeu que as reformas de base, entre elas a reforma agrária, seriam a única solução possível para o problema. 
Frente a este cenário, a questão social foi relegada a uma condição de epifenômeno, o que resultou, em termos práticos, a ser relegada a mero assistencialismo, exercido muitas vezes dentro do próprio Estado. $^{2}$

A partir da luta pela redemocratização, a sociedade civil brasileira começa a apresentar um variado protagonismo em diversas arenas públicas no País. Até então, a sociedade no Brasil havia sido considerada um ator muito secundário, devido à sua fragilidade histórica e pela própria descrença em sua capacidade de organização, mobilização e eficácia, qualidades estas que sempre foram reclamadas ao Estado, em que pese, também, ele não as ter mostrado. Nos últimos trinta anos, a sociedade começa a tomar novos contornos: a luta pela democratização, o surgimento dos novos movimentos sociais e até a própria acelerada urbanização trouxe este novo ator, que diferente dos partidos políticos, busca fazer ouvir sua voz fora dos espaços tradicionais da política. As vitórias dessas novas forças são muitas e podem ser verificadas nas lutas das mulheres, dos negros, dos homossexuais, dos agricultores sem terra e até mesmo dos indígenas, certamente, o segmento mais marginalizado no País.

Se, por um lado, não se pode deixar de reconhecer uma mudança significativa na qualidade da sociedade civil brasileira, por outro, devese ter presente que estes níveis de organização não chegaram à população mais pobre. Estes contingentes populacionais estão, em sua grande maioria, em cidades de menos de 50.000 habitantes na Região Nordeste do País, havendo também fora desta região bolsões significativos de pobreza nas áreas metropolitanas das grandes cidades, geralmente capitais de Estados (Belik \& Del Frossi, 2003). Mesmo considerando a sociedade civil como um conjunto heterogêneo quanto a classe, genro, etnia, raça cultura, níveis de educação formal, dificilmente pode-se pensar em incluir nesse conjunto uma população esfomeada, que vê seus filhos morrerem ainda no primeiro ano de vida de doenças simples ou erradicadas nas partes mais ricas do País.

A parcela organizada da sociedade civil, além da defesa de suas próprias lutas, envolveu-se, principalmente nos últimos vinte anos, em ações solidárias no sentido de incrementar as condições de vida 
da população mais pobre. Desta forma, junto às tradicionais ações de caridade, aparecem movimentos, novas ONGs, Igrejas, liderando campanhas pela cidadania, contra a fome, a desnutrição, etc. Tais ações tomam um vulto considerável na década de 1990 . $^{3}$

Antes de passar para a análise propriamente das ações contra a forme no Brasil na década de 90, faz-se necessária uma discussão, ainda que rápida, sobre a relação sociedade civil e Estado, na perspectiva de tomar a primeira como uma substituto do segundo. Uma questão particularmente importante é quando o Estado abre mão de políticas públicas em favor de ações de organização da sociedade. O senso comum sobre a eficiência da última deve ser enfrentado, antes de tudo, chamando a atenção de que a política pública tem um princípio de igualdade e universalidade que não faz parte da natureza das ações da sociedade civil. Por exemplo, uma política pública de imunização através de vacina contra uma moléstia fatal, necessita atingir o conjunto da população para ser exitosa. Já uma ação de uma organização da sociedade civil pode ter seu êxito computado a partir do número de pessoas envolvidas, de quantidade de trabalho voluntário despendido, dos recursos disponíveis. Em um cenário específico, uma ação da sociedade civil pode, inclusive, ser mais eficaz do que a ação do Estado, mas sempre está sendo perdido o caráter de direitos da população atendida. Os cidadãos só podem exigir seus direitos à saúde, à educação, à alimentação ao Estado, nunca a uma organização da sociedade civil.

Em relação à questão em que este artigo se concentra, a análise de Íris Young (2000) sobre os limites da sociedade civil é muito promissora. Young examina duas funções da sociedade civil, a de autodeterminação e a de autodesenvolvimento, argumentando que a sociedade tem plenas condiçes de realizar a primeira, mas não a segunda. Avançando no argumento, Young aponta que os defensores da autodeterminação como uma posição libertária em relação ao Estado (comunitários, libertários e neomarxistas) como posições que não tomam em consideração a justiça social, que envolveria mais do que autodeterminação, envolveria o que chama de autodesenvolvimento: "meeting people's basic needs for food, shelter, health 
care, and so on. It also entails the use of resources for reducation and training. (...) Because this is so, pursuit of justice as selfdevelopment cannot rely on the communicative and organizational activities of civil society alone, but requires positive State intervention to regulate and direct economic activity" (Young, 2000, p.184).

A distinção entre autodeterminação e autodesenvolvimento mostra-se muito promissora para enfrentar a problemática da sociedade civil e sua relação com o campo político, pois permite que se distingam, claramente, as possibilidades e os limites, sem cair em maniqueísmos muito em voga, que atribuem à sociedade todos os méritos e também todas as responsabilidades na manutenção do regime democrático. Neste tipo de postura, a presença do Estado é sempre vista como limitadora. Young argumenta que a sociedade civil forte é eficaz para produzir a autodeterminação, o que se reflete em independência em relação ao Estado e em uma postura crítica e cidadã; no entanto, não tem as condições necessárias para enfrentar a problemática que o autodesenvolvimento pressupõe. É nesta segunda posição que se encontram as ações contra a fome, que passarei a analisar a seguir.

\section{A luta contra a fome na década de 90}

a) Pastoral da Criança

A ação da Pastoral da Criança, no que se refere ao trabalho de combater a subnutrição e a fome infantil, é, sem dúvida, a mais bem-sucedida iniciativa não governamental no País. Mesmo o Estado brasileiro, em seus diferentes governos, nunca atingiu os resultados da Pastoral. Os dados da organização são eloqüentes e corroboram a hipótese, muito repetida, de que as organizações da sociedade civil estão melhor instrumentalizadas do que o Estado para atuar na área social. Segundo dados da própria entidade para o ano de 2001, a Pastoral atuava nos 27 Estados brasileiros, atingindo 64\% dos municípios, isto é, o impressionante número de 3.555 municípios, tinha 32.743 comunidades cadastradas, acompanhava, em média, 1.135.969 famílias por mês, tendo um número aproximado de 153.000 voluntários. 
Além disto, tinha programa de rádio transmitido por 1.343 rádios, atuava em projetos alternativos de criação de renda, de acompanhamento de idosos, entre outros (Pastoral da Criança, 2003).

Os números da Pastoral facilmente levam os apreciadores mais apressados das intervenções da sociedade civil a deixarem de considerar as especificidades desta organização, que a diferencia dos demais grupos da sociedade civil, e, entre as quais, duas são fundamentais para se avançar no exame desta organização. A primeira diz respeito à sua origem e forma organização; a segunda, ao seu financiamento. A Pastoral da Criança tem um mito fundador: uma conversa entre o Cardeal Arcebispo de São Paulo, na época Dom Paulo Evaristo Arns, e o Diretor Executivo do Unicef, em Genebra, no ano de 1982, quando o último teria convencido Dom Paulo que "a igreja poderia ajudar a salvar milhares de vidas de crianças que morriam de doenças facilmente previníveis". Voltando ao Brasil, Dom Paulo teria conversado (por telefone) com sua irmã e médica pediatra sobre a possibilidade levantada em Genebra. Um ano após, a Conferência Nacional dos Bispos do Brasil indicou a doutora Zilda Arns para criar e desenvolver a Pastoral da Criança. Esta historieta da fundação da Pastoral aproxima-a muito das ações da sociedade civil, que são permeadas por uma espécie de voluntarismo e espontaneísmo. O exemplo é muito bom, pois muitas vezes se confunde espontaneísmo com falta de liderança; o que ele indica, entretanto, é a falta de responsabilidade pública no nascedouro, por não fazer parte de um conjunto de ações articuladas para resolver um problema.

O surgimento espontâneo tampouco pressupõe, obrigatoriamente, movimento popular e ações democráticas partindo da base da sociedade civil. No caso da Pastoral, ela nasce e é oficialmente uma organização da Igreja Católica, em que pese se autodefinir como "um organismo autônomo", que pretende um trabalho ecumênico. Sem colocar em questão o ecumenismo da organização, até porque não há razões para pensar que a Pastoral não atenda criança de todas as religiões, ela está profundamente enraizada na formidável estrutura da Igreja Católica no Brasil. Os números são eloqüentes: a Pastoral atinge 100\% das dioceses 
brasileiras e $61 \%$ das paróquias, isto é, 5.217 paróquias em todo o Brasil. ${ }^{4}$ Trata-se, pois, de uma organização que se ancora em uma das instituições mais bem enraizadas do país. ${ }^{5}$

É através desta formidável rede que a Pastoral chega às comunidades pobres. Segundo seus próprios dados, a organização funciona com mais de 153.000 voluntários, sendo que "mais de $90 \%$ dos voluntários são mulheres pobres". A Pastoral tem como principal atividade a luta contra a subnutrição, e como seu maior trunfo a receita de um farinha feita como produtos desdenhados por mercados e grandes atacados, como folhas de verduras, frutas e legumes etc. Responsáveis tradicionais pela alimentação da família, as mulheres são recrutadas como voluntárias e, segundo a própria Pastoral, "ao valorizar o protagonismo de cada um, voluntários e familiares, na transformação de sua própria realidade e na garantia da qualidade de vida para as crianças das comunidades em que vivem com suas famílias, a Pastoral rompe o ciclo da exclusão que faz milhões de

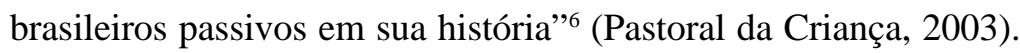

A idéia do rompimento da exclusão é especialmente interessante. É difícil estabelecer uma linha entre quem está incluído e quem está excluído. O caso da Pastoral é paradigmático. A inclusão aqui aparece como a oportunidade de se sentir pertencente a uma comunidade e agir dentro dela como reprodutora de uma idéia - no caso a da luta contra a desnutrição infantil. No texto de apresentação da Pastoral fica claro o seu objetivo de ajudar a organizar as populações para participarem da sua atividade e da vida pública: "O trabalho capilarizado dos mais de 130 mil líderes comunitários, que moram e atuam na própria vizinhança, é essencial para identificar focos de dificuldades no relacionamento entre as famílias e entre as pessoas da comunidade, assim como ajuda a organizar essas populações para participarem das decisões sobre as políticas públicas que os afetam" (Pastoral da Criança, 2003).

A intervenção da Pastoral aponta para dois importantes aspectos na relação da sociedade civil com as populações excluídas. $\mathrm{O}$ primeiro diz respeito à presença de uma organização poderosa e 
anterior a qualquer movimento da sociedade civil, a Igreja Católica, o que leva ao segundo aspecto igualmente importante, a presença de um elemento hierárquico, claramente estruturado de forma piramidal, onde existe um núcleo de decisão fora da comunidade. Nas décadas de 1970 e 1980 foram centrais na organização popular no Brasil as Comunidades Eclesiais de Base da Igreja Católica, que tiveram grande influência entre os grupos de esquerda no País e na própria organização dos sem-terra. A ação da Pastoral, no entanto, parece ter outra característica, porque no caso das CEBs tratava-se, em grande medida, de organizar a sociedade para se contrapor ao Estado autoritário dominado pelos militares; no caso da Pastoral, a questão é estabelecer uma colaboração com o Estado para tratar de um problema social grave. Isto faz toda a diferença em termos de organização da sociedade civil. Metodologicamente, é muito difícil averiguar as transformações ocorridas em termos de reconhecimento de cidadania nos grupos que tiveram contato com os agentes da Pastoral, entretanto, deve-se sempre ter em mente que se trata de um trabalho focado, que reforça o papel tradicional da maternidade. Extratos de uma entrevista da doutora Zilda Arns, líder e idealizadora da Pastoral, apontam para duas dimensões muito distintas, apesar de complementares. Em primeiro lugar, aparece uma posição de autoridade: "Por minha experiência profissional, como pediatra e sanitarista, senti que este trabalho de redução da mortalidade infantil seria bem-sucedido. Deveria ter um verdadeiro espírito missionário, de amor ardente que não espera, mas que vai ao encontro daqueles que precisam, e que o trabalho deveria ser ecumênico e sem preconceitos, pois a caridade é o maior mandamento" (Pastoral da Criança, 2003).

A autoridade é dada pela competência profissional e pelo apelo à religiosidade - caridade como mandamento: é a partir desta posição que a Pastoral chega até as comunidades pobres. O segundo extrato permite observar a posição de liderança, quando Zilda Arns afirma: "A proposta é de que a produção aconteça nas comunidades e que as mães participem do processo, tanto colaborando com ingredientes como ajudando a preparar a farinha. Esta participação tem importância fundamental para o resgate da cidadania e da dignidade das mulheres". 
Uma indagação aqui se impõe: qual é o grau de liberdade de organização e deliberação destas comunidades pobres tendo em vista a presença da Pastoral? Não há dúvida que há uma mudança na vida destas pessoas, pelo menos no que diz respeito à saúde de seus filhos. Soma-se a isto, um conjunto de informações que a Pastoral traz para elas. Ainda não se pode minimizar o fato de que as mulheres que se envolvem como voluntárias podem ter aí sua única oportunidade de sair de casa, encontrar outras mulheres e conversar sobre seus problemas e expectativas Neste sentido, a presença de uma organização como a Pastoral em comunidades pobres, e desprovidas de qualquer recurso econômico, social e muitas vezes até educacional, provoca efeitos positivos colaterais, não planejados e, algumas vezes, até não desejados pela própria organização. Isto, no entanto, não é suficiente para diminuir os limites impostos por uma organização como a Pastoral à organização de setores populares.

Para avançar na questão dos limites das intervenções da sociedade civil, deve ser tomado em consideração o importante tema do financiamento. Os dados para o ano de 2001 da Pastoral são bastante reveladores: os recursos recebidos somaram 8,3 milhões de dólares, sendo que $76 \%$ deste valor vieram diretamente do Ministério da Saúde. Para o ano de 2002, foi assinado um novo convênio mais ou menos nas mesmas bases (20 milhões de reais). O principal financiador da Pastoral fora do governo tem sido, segundo os dados da entidade, o Programa Criança Esperança - uma parceria da Rede Globo de Televisão e Unicef. Trata-se, portanto, de uma vultuosa transferência de recursos do setor estatal para o privado, que se encarrega de uma ação pública, ${ }^{7}$ executando-a através do voluntariado de pessoas de muito baixa renda. Isto significa, pelos próprios dados da Pastoral, uma economia anual, para o Estado, de 70 milhões de dólares. ${ }^{8}$

Apesar do discurso de tipo libertário que percorre todas as publicações da Pastoral, o programa que visa resolver o problema da desnutrição infantil é uma ação de comprovada eficácia incorporada pelo governo, que passa a transferir responsabilidade para a organização. Esta adquire grande centralidade e popularidade na mídia 
e na opinião pública, à medida que consegue, através do trabalho voluntário de mulheres, muitas vezes desempregadas pela crise econômica, alcançar resultados bastante surpreendentes. A Pastoral reforça, assim, o senso comum de que o Terceiro Setor é mais ágil e tem uma relação custo-benefício muito mais positiva do que o Estado.

A Pastoral tem tido grande centralidade no programa Fome Zero, sua criadora e coordenadora; também é membro do Conselho Nacional da Saúde e do Conselho Nacional de Segurança Alimentar (Consea). Este é, sem dúvida, o programa não-governamental mais bem-sucedido no Brasil, cujo princípio importante é ensinar uma nova forma de alimentação; entretanto, deve-se ter presente algumas outras questões que esse êxito traz consigo e que são preocupações centrais deste trabalho: a primeira diz respeito à fome no Brasil como uma questão passível de ser resolvida por ações de caridade, ${ }^{9}$ o segundo, e quase como conseqüência, é a desresponsabilização do Estado com a questão. Um cenário é uma política pública com metas a serem alcançadas, orçamento a ser aplicado e controle, pelo menos interno, de seu cumprimento; outro, muito distinto, é a ação benemérita, que não tem de cumprir metas, nem prestar contas diretamente ao setor público.

A ação da Pastoral é um exemplo muito claro da transferência de recursos e de responsabilidades do Estado para uma organização da sociedade civil e em decorrência disso estão os limites da liberdade de organização das comunidades pobres, que entram nos programas oferecidos. Neste caso, tais limites estão pautados por duas condições principais: a necessidade da eficácia calcada em uma instituição que tem como base uma estrutura hierárquica, e a própria ideologia da instituição, presente no trabalho da Pastoral com as mães: a intervenção do pensamento da Igreja Católica é bastante transparente nas chamadas ações paralelas. Entre estas ações encontra-se, por exemplo, o Planejamento Familiar pelo Método Natural (método do colar): "ações de informação aos casais e jovens sobre os métodos de planejamento familiar, com ênfase nos métodos naturais" (Pastoral da Criança, 2003).

A relação entre a sociedade civil (os incluídos), no caso a Pastoral, e os excluídos, aqueles que têm filhos com problema de 
desnutrição, ocorre de forma hierárquica e pautada pelos princípios da Igreja, mesmo assim, não se pode deixar de considerar, que a chegada da ação da Pastoral em comunidades pobres e distanciadas de qualquer recurso se não provoca mudanças no sentido de empoderamento, pelo menos cria espaços para novas formas de interação e comunicação entre as mulheres antes, muito possivelmente, isoladas em suas casas.

\section{b) Ação da Cidadania contra a Fome}

Se a Pastoral da Criança tem sido, até hoje, no Brasil, a mais eficaz ação contra a fome, mesmo que focada na desnutrição infantil, foi, sem dúvida, a campanha liderada por Herbert de Souza, em 1993, que ganhou mais popularidade e inspirou com mais força ações governamentais, inclusive as que foram tomadas pelo Governo do PT a partir do ano 2003. A campanha conhecida como "Ação da Cidadania contra a Fome" tem pontos comuns, mas também muitas diferenças em relação à Pastoral. Para os propósitos deste artigo alguns destes pontos são especialmente importantes. Quatro similitudes devem ser destacadas: a proximidade com a Igreja Católica; a presença de uma liderança carismática; a relação com o Estado; a crença na capacidade da sociedade civil de responder com soluções aos grandes problemas nacionais.

Não se pode entender a "Ação da Cidadania contra Fome" sem tomar em consideração a existência do Instituto Brasileiro de Análises Sociais e Econômicas (Ibase) e a figura carismática de Herbert de Souza, o Betinho: sociólogo, militante da esquerda católica, conhecido no Brasil antes mesmo de sua atuação pública por ser irmão do mais famoso cartunista brasileiro à época e, por isto, citado em uma música popular de grande sucesso. ${ }^{10}$ Betinho voltou ao Brasil em 1979, após anos de exílio, com o propósito de estabelecer um campo de luta independente dos partidos políticos. Ajudou a criar o Instituto de Estudos da Religião (ISER) e, em 1980, criou o Ibase, que teve, inicialmente, o propósito de criar um banco de dados que fornecesse informação independente aos movimentos sociais. Ao 
longo dos últimos 20 anos, essa organização tornou-se um dos grandes centros de luta pela democracia, pela ética na política e pela justiça social. Em que pese sua independência, o Ibase sempre esteve marcado por suas relações com a Igreja Católica e com o Partido dos Trabalhadores. Carlos Fico, em sua obra sobre a organização, afirma que esta teve um grande apoio por parte de nomes como Dom Paulo Evaristo Arns, Dom José Maria Pires, Dom Antonio Fragoso, Dom Pedro Casaldália, Leonardo Boff, entre outros. Além disto, a CNBB teria assegurado recursos para o funcionamento da ONG, o que depois não se concretizou devido às desavenças internas entre os bispos sobre a importância da iniciativa. Entretanto, em 1993, quando da campanha que aqui interessa, novamente se vê a presença forte da Igreja (Fico, 1999, p. 27).

A “Ação da Cidadania contra a Fome" nasceu como decorrência de uma discussão interna, que o Ibase estava tendo, em função da mobilização do país contra os desmandos do então presidente Collor de Mello. O Instituto estava levando a efeito uma campanha, reconhecida entre os setores mais cultos e politizados da sociedade como de grande relevância, o "Movimento pela Ética na Política", que, no entanto, segundo o relatório anual da instituição, não havia alcançado a publicidade que necessitaria. Os coordenadores do Ibase entenderam que havia chegado a hora de reunir a experiência da instituição com a mobilização popular, decorrente do impeachment de Collor, para promover uma grande campanha. Novamente, constata-se a presença da Igreja: foi Dom Luciano de Almeida "que cunhou a frase que instituiria a Campanha" (Fico, 1999, p. 125). Em março de 1993, no primeiro encontro "Pela Ética na Política", formouse a secretaria Executiva Nacional da Ação da Cidadania, quando foi lançado um manifesto nacional. Desta secretaria faziam parte a Cáritas ${ }^{11}$ e a CNBB, duas importantes instituições católicas. Devese pontuar que a presença da Igreja Católica, de fato importante na Campanha, tem um caráter bastante distinto da que foi observada em relação à Pastoral, que é uma organização da própria Igreja. A "Ação da Cidadania" foi um movimento realmente da sociedade civil, com autonomia em relação à hierarquia da Igreja. 
Outro aspecto comum entre estes dois movimentos é terem uma relação próxima com o Estado, também marcada por distinções. No caso da "Ação...", deve-se considerar que o país encontrava-se em um período bastante excepcional, governado pelo vice-presidente Itamar Franco após o impeachment de Collor. A aproximação com o governo ocorreu através de Luiz Inácio Lula da Silva, então presidente do PT, praticamente o único partido que havia ficado fora da aliança de sustentação do governo.

Lula entregou a Itamar uma proposta de combate à fome com a sugestão da criação de um Conselho de Segurança Alimentar e sugeriu, na oportunidade, que Betinho fosse seu presidente. $\mathrm{O}$ Conselho foi criado com a sigla de Consea e seu presidente foi Dom Paulo Morelli, bispo de uma das regiões mais violentas do País, na baixada fluminense e, tradicionalmente, ligado à esquerda da Igreja Católica. O Consea foi fechado durante o governo de Fernando Henrique Cardoso, quando as questões sociais ficaram sob a responsabilidade da primeira dama, a antropóloga Ruth Cardoso. Foi refundado com a posse do presidente Lula, em janeiro de 2003.

É bastante fácil verificar as formas distintas como a Pastoral e a "Ação da Cidadania" se relacionam com o Estado. Enquanto a Pastoral toma para si uma função estatal, assumindo a tarefa através do recebimento de recursos, a "Ação" busca no Estado a oficialização de uma política pública. Todavia, deve-se aqui prestar atenção em um interessante detalhe que permite apreender a intrincada textura das relações de ONGs com a sociedade civil e com os partidos políticos. A visita de Lula a Itamar concomitante ao lançamento da "Ação..." e a indicação do nome de Betinho para a presidência do Consea não deixam dúvida das relações entre o PT e o Ibase: Lula vai ao Presidente da República como presidente do maior partido de oposição ao governo e não como integrante da campanha ou da ONG. Inclusive a campanha popular que se segue é proposta por Betinho, não como uma colaboração com o governo, mas em contrapartida à posição oficial. ${ }^{12}$ Portanto, apesar do Ibase ter, tal como a Pastoral, uma relação com o Estado, a "Ação..." foi paralela e independente das políticas do governo. 
Todavia, a grande distinção entre a Pastoral e a "Ação..." foi a forma como a última organizou seu movimento. Enquanto a Pastoral teve uma organização claramente hierárquica, que a partir da coordenação de Zilda Arns chega até as comunidades, através das dioceses e paróquias, a proposta da "Ação..." era a descentralização. A idéia central era o recolhimento de alimentos não perecíveis por comitês organizados por cidadãos em todo o País, de forma independente. Não havia coordenação geral, nem era necessária autorização para o funcionamento. Havia, em Brasília, uma Executiva Nacional que, segundo Fico, era apenas responsável pela circulação de informações entre os comitês. A idéia de Betinho na ocasião expressava-se da seguinte forma: "As palavras-chave são descentralização, autonomia e iniciativa. O movimento é totalmente descentralizado, uma vez que ele não pertence a uma pessoa ou grupo, mas à cidadania, à sociedade. Cada cidadão é responsável por seus atos. O cidadão se organiza, mas com total liberdade. Cada comitê define o que fazer na sua luta contra a fome" (Fico, 1999, p. 123).

A "Ação da Cidadania contra a Fome" foi lançada oficialmente por Herbert de Souza em rede nacional de televisão, em cadeia requisitada pelo governo federal e provocou, certamente, o maior movimento cívico que o País viveu em sua história. ${ }^{13}$ Além do próprio apelo à cidadania, alguns fatores colaboraram para isto, em primeiro lugar, a sensação que o País vivia de que havia sido a mobilização da sociedade civil que obrigara o Congresso Nacional a votar o impeachment de Collor. Os brasileiros, que historicamente sentemse impotentes frente ao Estado e às elites dirigentes, percebiam-se como passíveis de liderarem ações políticas de longo alcance. Somava-se a isto a figura altamente carismática de Betinho, que nesse momento já estava fisicamente muito debilitado devido à manifestação da AIDS. Betinho parecia morrer em público clamando à população para se unir contra a fome. ${ }^{14}$

Organizaram-se comitês de norte a sul do País, nas universidades, escolas, clubes, repartições públicas, empresas privadas, associações de bairro, sindicatos e em comitês de rua formados a 
partir da reunião de amigos. Arrecadaram-se muitas toneladas de alimentos não perecíveis. Pela própria natureza da campanha, não há dados sobre o número de pessoas que se envolveram nos comitês e muito menos das pessoas que fizeram doações, mas certamente são números impressionantes. A campanha nunca acabou, mas, com o tempo perdeu espaço na mídia e na vida dos brasileiros, a maioria dos comitês se desfez, outros mantêm-se ativos apenas durante as festividades de fim de ano, quando há um grande apelo à solidariedade. Houve grande distribuição de cestas básicas, mas muito desperdício, falta de coordenação na distribuição e, exatamente por sua natureza, grande descontinuidade. ${ }^{15}$ Qualquer programa social que tenha como única fonte de recursos a disponibilidade e a boa vontade de um voluntariado, não pode garantir nenhum tipo de continuidade. Os brasileiros com fome continuaram na mesma situação, após um ano de campanha.

Em relação à Pastoral, três diferenças ainda devem ser pontuadas. Em primeiro lugar, o grau de eficácia. Não há dúvida que a Pastoral alcançou muito mais eficácia em atingir seus objetivos. Isto poderia ser atribuído a organização hierárquica e à forte presença da Igreja Católica não apenas como apoiadora, mas por ter colocado à disposição sua formidável rede de dioceses e paróquias. Se, por um lado, não se pode deixar de considerar esta situação especial, por outro, seria apressado atribuir a isto toda a causa da eficácia da Pastoral. Deve também ser considerado o fato de a Pastoral ter uma atividade focada na subnutrição infantil e como objetivo a sua superação através de um complemento alimentar, enquanto a "Ação..." tinha um objetivo grandioso, enfrentar a fome no Brasil, que atingia 11 milhões de famílias, através de uma ação completamente voluntarística. Aí também reside a segunda razão fundamental que diferencia os dois movimentos quanto à sua eficácia: a questão do voluntariado. Na Pastoral, os recursos não dependem do voluntariado, são garantidos, em sua grande maioria, pelo Ministério da Saúde, e o voluntariado ocorre através de uma ação de convencimento nas comunidades carentes usando o trabalho voluntário de mulheres pobres. $\mathrm{Na}$ "Ação..." tudo é voluntário, desde os locais para 
estabelecer comitês até a distribuição, doação e recolhimento de alimentos.

Estamos frente, portanto, a duas ações de naturezas completamente distintas, a primeira pode ser classificada como atividade do Terceiro Setor, isto é, aquelas atividades que nos últimos 20 anos têm sido deslocadas do Estado para as organizações da sociedade civil, desresponsabilizando o Estado de políticas universalistas e transformando-as em ações públicas que, embora eficazes, são de alcance limitado; neste tipo de ação, a eficácia é medida pelo aumento do número de atendimentos, não pelo atingimento do universo. Não se pode esperar da Pastoral, o que se deveria esperar do Estado, isto é, a solução do problema da desnutrição.

As atividades da "Ação..." estão mais próximas de modelos de organização democrática da sociedade civil através da construção de espaços públicos. Há na "Ação...” um trabalho real de construção de cidadania, de empoderamento através da capacidade de cada comitê tomar decisões autônomas. Todavia, também, nesta ação há uma transferência de responsabilidade do Estado para a sociedade, com o agravante de o Estado não entrar com nenhum recurso.

Finalmente, no que concerne à comparação destes dois movimentos, cabe uma observação sobre o espaço que ocupam na sociedade civil: os movimentos relacionam-se de forma distinta com os setores incluídos e excluídos. A Pastoral presta um serviço e busca construir uma ideologia de caráter religioso entre as populações que atende. A distinção entre a Pastoral e aqueles que estão sendo atingidos pelo programa é clara: o trabalho voluntário tem uma relação hierárquica com a Pastoral e não tem um propósito inclusivo. A “Ação..." tem uma proposta dirigida essencialmente para a construção de espaços públicos de exercício da cidadania. Trata-se de uma experiência nova e com potencialidade como modelo de democracia participativa, ${ }^{16}$ entretanto, mantém, tal como a Pastoral, uma clara divisão entre incluídos (os componentes dos diversos comitês) e os excluídos, aqueles aos quais se dirige a ação, isto é, aqueles que recebem a comida arrecadada. 
É mister anotar a complexidade destas ações da sociedade civil ou do chamado Terceiro Setor. Nestes dois casos examinados, por parte da Pastoral verifica-se uma estrutura hierárquica, pouco democrática, muito personalista, mas com um trabalho que propõe a modificação das condições reais de sobrevivência de um número significativos de crianças no país; a "Ação..." por seu lado, é infinitamente mais democrática, tem ligações assumidas com posições e partidos de esquerda, mas sua ação está muito mais próxima da simples esmola do que o trabalho da Pastoral. No caso da "Ação...", existe um trabalho importante, mas não de inclusão, já que ele se dirige a um população já incluída, que é capaz de se organizar em comitês ou doar alimentos. O trabalho importante é no sentido de promover uma organização não hierárquica, criando a possibilidade de espaços públicos potencialmente capazes de oferecer esferas diferenciadas de discussão e participação política. Esta potencialidade pode ter sido minimizada pelo tipo de sentimento que a campanha despertou em grande parte da população, isto é, de espírito de caridade, e não, como pensava o criador da Campanha, de despertar uma nova cidadania. No entanto, não houve nenhum trabalho no sentido de organizar as pessoas que recebiam os alimentos, que foram protagonistas apenas como clientes. Já a Pastoral, apesar de seus traços hierárquicos ao mobilizar as mulheres para o trabalho voluntário, não tem condições de controlar o desenrolar destas vidas e as conseqüências que esta mobilização pode provocar. Neste sentido, as possibilidades de inclusão aparecem mais fortes no trabalho da Pastoral do que no trabalho do Ibase, o que revela toda a complexidade da ação das organizações não-governamentais.

\section{c) Para além da Pastoral e da Ação da Cidadania ${ }^{17}$}

Três tipos de ONGs que têm como alvo a questão da fome no Brasil serão aqui examinadas. Um primeiro conjunto é formado por aquelas que surgiram diretamente da campanha da "Ação da Cidadania contra a Fome", formando grupos que se profissionalizaram como militantes da luta contra a fome. O segundo conjunto é o de ações tradicionais de caridade que se transformaram em ONGs, 
possivelmente pelas possibilidades que este tipo de organização oferece. O terceiro conjunto é formado de ONGs internacionais que se estabelecem no Brasil com o mesmo propósito de lutar contra a fome. Em qualquer um dos conjuntos veremos reproduzida a idéia da questão social como uma questão da sociedade e não do Estado.

Das ONGs derivadas da campanha liderada por Betinho, a tendência foi alargar as atividades, muitas vezes deixando o recolhimento de alimento em um segundo plano. Um exemplo bastante ilustrativo deste tipo de organização é a ONG "Ação da Cidadania" com sede em São Paulo, que surgiu no mesmo ano da Campanha e se auto define como "a representação jurídica de parcela desses movimento para cobertura de âmbito estadual". Na apresentação de suas atividades é interessante perceber o alargamento das atividades em relação ao propósito inicial. Em seu site lê-se: "A Ação Cidadania São Paulo operacionaliza sua intervenção pelos comitês, projetos, movimentos e entidades sociais na distribuição de alimentos e manutenção de projetos de geração de emprego e renda. Desde 2000 a atenção e esforços também se dirigem a projetos de capacitação de multiplicadores de planejamento estratégico e à formação de quadros profissionais destinados a agentes de comitês, organizações ou de projetos sociais" (Ação da Cidadania, 2003).

Cabe aqui um parêntese para introduzir um aspecto que merece ser tomado muito cuidadosamente, quando estamos examinando a presença das ONGs como um grande protagonista da sociedade civil e que é facilmente perceptível na organização que está servindo com ilustração neste momento. À medida que uma campanha para arrecadar alimentos formaliza-se e torna-se uma ONG, ela entra na dinâmica deste tipo de organização, que é a de montar projetos para, a partir deles, arrecadar fundos para cumprir o que chamam de missões e para o seu próprio funcionamento (aluguéis, pagamentos de funcionários e outras despesas menores). Daí, a centralidade da missão pode ser deslocada. Se observarmos os projetos levados a efeito por esta ONGs, verificamos que apenas três entre os nove apresentados se relacionam com a arrecadação de alimentos: "Natal sem fome", que recolheu doações em uma praça no centro da cidade 
de São Paulo e os distribuiu para 50.000 pessoas; "Café da manhã para o desempregado", que distribuiu 5.000 cafés da manhã no dia em que se comemora o Dia Mundial da Alimentação; "A Cantina do Betinho" com a "venda de refeições aos domingos, cuja renda é revertida para as cozinheiras de baixa renda, moradoras de Santa Cecília." São estas, pois, todas ações de baixo impacto, que possuem uma eficácia eminentemente simbólica. ${ }^{18}$

Entre as ações que a ONG denomina programas, também se percebe que a arrecadação de alimentos é apenas uma pequena e menos importante parte. Quando os dados foram retirados da página da Internet, em junho de 2003, a ONG ainda estavam implementando um site para recebimento permanente de doações, mas havia também cursos de formação em Comunicação Básica, de Agentes de Redes de Comunicação e Informação e de Cooperativismo, de Gerenciamento de Entidades, de Formação de Trabalhadores para Entidades e Movimentos Sociais. Também é listado como programas o que organização chama de "Interferência no Processo Democrático, nas Políticas de Direitos e na Construção de Políticas Públicas", o que resultou em cartilhas para o voto, sobre segurança alimentar, atuação em conselhos e em fóruns, seminários, debates etc. Nota-se no caso desta ONG, nota-se um claro deslocamento da ação prática direta com as populações excluídas para um trabalho muito mais aproximado de uma atividade acadêmica de promoção de cursos e cartilhas.

Um segundo exemplo de ONG inspirado no trabalho de Betinho é "Centro de Defesa da Vida Herbert de Souza" (CDVHS), fundado em 1994 na periferia da cidade de Fortaleza. Esta é um tipo de organização que tem um foco local, no caso uma região da periferia da cidade, e está diretamente relacionada às Comunidades Eclesiais de Base da Igreja Católica (CEBs). Dois aspectos são importantes de serem ressaltados em relação a esta ONG. O primeiro é o discurso grandiloqüente de uma organização de caráter local, quando se autodefine (a autodefinição é a expressão usada pela ONG): “o Centro Herbert de Souza quer ser uma organização colaborativa e aprendente (sic), capaz de potencializar o surgimento de uma sociedade mais 
democrática, com igualdade de gênero, social, econômica, cultural e política e um mundo em que os diferentes sujeitos sociais, de forma colaborativa e autônoma, lutem contra a pobreza e a injustiça". O segundo aspecto a ser pontuado em relação a esta ONG é a total ausência de qualquer referência a campanhas de arrecadação de alimentos ou de qualquer outra ação deste tipo, mas com uma diferença fundamental em relação à ONG anterior, o Centro interage diretamente com as populações excluídas através de iniciativas tais como: "recuperção da auto-estima dos pobres"; "desenvolvimento de conhecimento, habilidades e competência"; "promoção de cooperação criativa explicada pelo centro como: a única saída para os pobres, pois o individualismo, a falta de inovação e de criatividade quando unidos à pobreza e à miséria provocam o conformismo e a falta de esperanças. Por isso, o CDVHS estimula momentos de convivência comunitária e promove mecanismos que favorecem a cooperação e a solidariedade; o empoderamento de pessoas e organizações populares"; "criação e fortalecimento de redes" (CDVHS, 2003).

O terceiro exemplo de ONG é o da "Ágora", que difere completamente dos dois anteriores, e que surgiu com a "Ação da Cidadania Contra a Fome" em 1993, com sede em São Paulo e Rio de Janeiro. Sua principal característica é ser uma organização de assessoria, mesmo na sua missão, espaço onde as ONGs se colocam na maioria das vezes a partir de uma visão libertadora, a "Ágora" coloca-se de forma bastante moderada: "Sua missão é promover o direito humano à alimentação e nutrição de seres humanos e suas comunidades, por meio da elaboração, divulgação, fornecimento e replicação de tecnologias e metodologias sociais adequadas; do assessoramento e da parceria com comunidades, movimentos sociais, empresas e organismos governamentais e da contribuição técnica e política para a inclusão do componente de Segurança Alimentar e Nutricional Sustentável e Cidadania em estratégias sociais, políticas públicas, projetos e programas governamentais ou não governamentais, em níveis local, nacional e internacional” (Ágora, 2003).

Os objetivos são amplos, mas bastante técnicos, e a ONG fazia parceria, na época em que os dados foram recolhidos (junho de 2003) 
com as seguintes agências governamentais: Ministério da Ciência e Tecnologia; Instituto de Colonização Agrária (Incra) - Ministério da Reforma Agrária; Ministério do Trabalho - Fundo de Apoio ao Trabalhador; Secretaria de Estado de Direitos Humanos; Ministério da Saúde; Ministério da Justiça; Governos do Distrito Federal, do Rio Grande do Sul, de Alagoas, de Minas Gerais, de São Paulo; Secretaria do Emprego e das Relações do Trabalho (SERT) do Estado de São Paulo. Também tinha parceria com a FAO, IFAD, Unicef e com um conjunto expressivo do que chama de sociedade civil internacional ${ }^{19}$ e com organizações privadas brasileiras, tais como Sebrae e Fiesp.

A “Ágora” desenvolve um número expressivo de projetos em diversas áreas ligados à questão da alimentação, desde tele-cursos, cestas da cidadania, combate à desnutrição infantil, mas a forma mais típica de sua intervenção é a da capacitação. Segundo os dados da própria ONG: "nos últimos seis anos, através de parcerias com os governos federal e estaduais e diversas organizações da sociedade civil, a Ágora capacitou cerca de 25.000 pessoas. Os cursos promovidos pela Ágora buscaram diferentes enfoques, visando atender demandas, tais como: capacitação gerencial básica, gestão de empreendimentos, informática, formação em direitos humanos, formação de agentes de crédito, alimentação e nutrição, gestão de fundos rotativos de empréstimos solidários, serviço civil voluntário, desenvolvimento local integrado e sustentável, formação de lideranças comunitárias e formação profissional e resgate cultural da raça negra" (Ágora, 2003).

O segundo conjunto de ONGs que fazem parte deste movimento geral, nascido em 1993, contra a fome no Brasil, são as instituições tradicionais de caridade que se tornaram organizações não governamentais. ${ }^{20}$ A principal característica destas organizações é a ação filantrópica, onde não aparece o discurso de igualdade, justiça social, como foi observado no conjunto anterior. Também se caracterizam por serem pequenas organizações com objetivos muito focados. Um bom exemplo deste tipo de organização é a ONG “Associação Prato Cheio”, fundada por universitários, em 2001, na 
cidade de São Paulo. Segundo sua página na Internet: “Atualmente são quinze voluntários, que num sistema de rodízio vêm coletando regularmente aos sábados, no Mercado da Cantareira (Mercado Municipal), uma média de 800 quilos de alimentos em boas condições (sempre supervisionados por uma nutricionista)" (Prato Cheio, 2003).

Também com o objetivo de coletar alimentos, um tipo de ONG com todas as características de instituição de caridade é a que se denomina "ABBP (Associação Beneficente Benedito Pacheco) - A turma da sopa". A organização apresenta-se através de dois personagens âncoras na construção do discurso voluntariado e da caridade: o criador e o recuperado. Ambos tem uma história e uma missão, o criador, é apresentado da seguinte forma: “ABBP começou em 1992 por uma iniciativa do Dr. Eduardo Ferraz de Mendonça. Ele estava assistindo televisão e ficou sensibilizado com a notícia de pessoas morrendo de frio nas noites de São Paulo. Comentou com um amigo e juntos resolveram arrecadar cobertores - conseguiram 350 - e saíram às ruas para distribuí-los. Enquanto cobriam nossos amigos de rua, foram conversando com eles e perceberam que além dos cobertores, eles precisavam de alimentos e carinho. Então resolveram fazer uma sopa e distribuíram na semana seguinte, e na outra, e na outra" (julho 2003). A história do recuperado (a criatura) é assim contada:. "Com a reintegração à sociedade do paraibano João Emiliano de Figueiredo (primeiro amigo a sair das ruas com a nossa ajuda), que era um morador de rua e hoje trabalha na associação ajudando a cozinhar a sopa, percebemos que poderíamos fazer muito mais pelo morador de rua e passamos a ter como meta principal a reintegração do morador de rua na sociedade" (ABBP, 2003).

Este tipo de associação tem alcance limitado, vive de doações e depende de voluntários para funcionar. Basicamente sua ação é distribuir sopa quatro vezes por semana e em três pontos específicos da cidade de São Paulo. Também busca emprego para pessoas que querem sair da rua. É particularmente interessante em todo o texto desta ONG o fato de chamarem os moradores de rua de "amigo", em um esforço claro de criar um cenário de solidariedade e respeito. 
O terceiro exemplo é particularmente ilustrativo para os nossos objetivos. Trata-se de uma ONG que começou sua atividade em 1999, mas tinha uma tradição como instituição filantrópica de 10 anos. Com sede em São Paulo, os Amigos do Bem atua no semi-árido nordestino, a região mais pobre do País. Começou distribuindo alimentos e gêneros de primeira necessidade no período entre o Natal e o fim do ano: “Ao longo de 10 anos de atividades, 168 mil famílias, - mais de 800 mil pessoas -, receberam, graças à ajuda de milhares de voluntários: alimentos, roupas, remédios, brinquedos, colchões, cadeira de rodas, atendimento médico-odontológico." A partir do ano da fundação da ONG, as atividades transformaram-se, tornando-se muito próximas das observadas no segundo conjunto. Houve, no caso dos Amigos do Bem, uma clara profissionalização, que pode ser observada tanto no foco de sua atuação, como no conjunto de projetos que propõe. Segundo os dados da instituição, em apenas um ano de atividades, a ONG Amigos do Bem: "Identificou e cadastrou mais de duas mil famílias; forneceu regularmente alimentos para retirar famílias de situação de risco; procedeu estudos de solo para agricultura; realizou prospecção geológica para a perfuração de poços artesianos; iniciou um programa de distribuição de sementes" (Amigos do Bem, 2003).

A comparação entre as atividades dos primeiros 10 anos e as atividades do pequeno período como ONG permite observar a diferença muito transparente entre uma instituição de caridade e uma ONG. A primeira está calcada em um trabalho voluntário simples e tem propostas quase simbólicas, isto é, durante uma semana ao ano distribuir alimentos. Quando se transforma, em ONG já aparecem propostas que exigem trabalho especializado e recursos de instituições de financiamentos. ${ }^{21}$

Nos projetos propostos pela ONG Amigos do Bem há um aspecto interessante e bastante raro nas instituições que se preocupam com a fome, que é a busca da transformação das condições de vida das populações atendidas, projetos como construção de cisternas, distribuição de sementes, construção de casas. Um projeto particularmente interessante é o da construção da "Vila Agrícola do Bem", que deve ser financiada pelas doações do "amigo do bem", 
isto é, qualquer pessoa que se proponha a fazer uma doação mensal maior de 101 reais. Não se trata de um tipo de reforma agrária, pois as famílias cadastradas não recebem terra, mas casa para morar e trabalho na terra em regime de CLT. O projeto, que até julho de 2003 não havia se implantado, tem pretensões de se multiplicar em muitas Vila Agrícolas do Bem: "implantação da Vila Agrícola do Bem, baseada em um modelo de entidade sem fins lucrativos, na qual, além da geração de emprego, renda e moradia para as famílias cadastradas pelos Amigos do Bem, seriam gerados recursos para a construção de novas vilas agrícolas em outras localidades carentes onde os Amigos do Bem atuam”.

Este é um tipo de intervenção muito particular da sociedade civil organizada em regiões de muita pobreza, com uma população completamente excluída, pois há no projeto uma proposta de inclusão onde o "incluído" aparece como um agente completamente passivo. Ele é escolhido, cadastrado e viverá segundo regulamentos propostos pela ONG. Não há dados disponíveis, mas certamente este tipo de empreendimento possui princípios rígidos e regulamentos que devem ser cumpridos pelos moradores que são selecionados pela ONG. Não se trata de uma vida comunitária organizada pela própria comunidade, mas de um projeto recebido pronto por pessoas que não tem influência sobre o projeto.

O terceiro exemplo de ONGs são as grande organizações internacionais que chegam ao Brasil na década de 90 , com o objetivo de implantar projetos contra a fome. Duas organizações são bons exemplos, a Care Brasil e a Actionaid Brasil, a primeira de origem norte americana e a segunda de origem inglesa. As duas organizações têm características muito próximas, são potências internacionais, com grande experiência, com projetos próprios e financiamento de fundações internacionais, as duas chegaram no fim da década de 90 ao País. A forma como estas grandes organizações tratam a questão da pobreza e dos pobres não se diferencia fundamentalmente da postura das instituições de caridade que foram focos anteriormente. Em nenhum momento, estas ONGs falam em projetos nacionais, ou em parcerias com o governo, mas, sim, do pobre e da forma como 
ajudá-lo a sair da pobreza. A Care Brasil assim descreve a sua missão: "servir às comunidades e às famílias mais pobres do País, potencializando a experiência, a diversidade e os recursos existentes, tanto na sociedade brasileira, quanto na Care Internacional. Queremos ser um agente catalisador de processos de transformação social que gerem soluções duradouras para a "erradicação da pobreza". A Actionaid tem também o propósito de gerar soluções para a pobreza. Sua missão é assim colocada: erradicar a pobreza através do trabalho com os pobres para ajudá-los a alcançar seus direitos básicos, superando a exclusão, a injustiça e a desigualdade" (Action Aid, 1993).

Ambas as organizações pretendem erradicar a pobreza no Brasil: a primeira com recursos próprios e da sociedade; a segunda com um trabalho junto aos pobres para lhes explicar seus direitos. Ora, tais propósitos parecem estar entre a ingenuidade e a má intenção para qualquer entendedor mediano da problemática brasileira. Entretanto, se tomarmos as ONGs que constroem um discursos de textura mais esquerdista, observaremos que é uma outra face de uma mesma moeda. Se entre aquelas o discurso era da libertação e justiça social através da interferência da ONG, estas trazem sua experiência oferecendo-se como agente da transformação.

Também é interessante notar em relação a estas duas grandes organizações internacionais, que seus projetos e programas não se diferenciam dos projetos levados a efeito por ONGs nacionais, são ações pontuais. A Care apresenta em sua página na Internet apenas dois projetos, o projeto sul da Bahia ("O projeto tem como objetivo contribuir para a melhoria da qualidade de vida das populações de cinco áreas - Ilhéus, Itacaré, Una e Itabuna - na região cacaueira do sul da Bahia") e o projeto Nova Onda da Maré, que visa contribuir para o exercício da cidadania dos moradores de Nova Holanda, em particular as crianças, por meio de: "acesso às novas linguagens, que interajam com as usuais; ampliação do capital educacional, cultural, social e simbólico; subsídio à produção de alternativas e reivindicações comunitárias no campo das políticas sociais, em particular no âmbito da educação, da cultura e da geração de renda; inserção qualificada dos jovens no mercado de trabalho" (Care, 2003).

O Actionaid, não obstante ter um maior número de projetos também são eles muito pontuais, tais como oferecer atividades de 
lazer a crianças e adolescentes de uma favela em São Paulo; alfabetizar adultos na cidade de Cabo de Santo Agostinho, em Pernambuco; "fortalecer (sic) o papel das mulheres que são responsável pela quebra do coco do babaçu em Mearim no Maranhão; ajudar a resolver em parte o problema da dificuldade de acesso à água potável enfrentada pelos moradores da Zona do Agreste pernambucano".

\section{À guisa de conclusão}

$\mathrm{Na}$ introdução deste artigo foi levantada uma hipótese sobre a questão da intervenção das ONGs quanto ao problema da fome no Brasil, que apontava para limitações da intervenção da sociedade civil. Apontei também, a título de introdução, as duas noções cunhadas por Íris Young, autodeterminação e autodesenvolvimento. O exame das ações de um conjunto de ONGs, descritas nas páginas anteriores, fornece indicadores fortes dos limites da sociedade civil em tomar para si funções precípuas do Estado, reforçando assim a tese de Young de que o autodesenvolvimento carece da intervenção estatal.

O exame do conjunto de ONGs leva à confirmação de que, na medida em que a questão social não é tratada pelo Estado, que se concentra na tese do crescimento econômico para tirar a população da miséria, ela passa a ser trabalhada pelos agentes da sociedade civil como uma questão pontual isolada, o que não permite políticas universalizantes, que mudem a qualidade de vida das populações em situação de miséria. As ações tomadas em relação a elas são reflexos tanto da natureza da intervenção da sociedade civil, quanto da própria forma como a questão é pensada. As ONGs das mais diferentes posições ideológicas, tamanho e missões têm todas um caráter de filantropia, quando se trata de distribuir alimentos. De fato, não poderia ser de outra forma, até pela falta de capacidade operacional destas organizações. O caráter de caridade fica muito claro na presença de instituições religiosas, especialmente da Igreja Católica e do Espiritismo, duas religiões bastante envolvidas, em toda a sua história, com a noção de caridade. É interessante notar que, à medida que as ONGs se profissionalizam, deixam de colocar seu foco principal na questão da fome e passam a propor e a executar projetos de profissionalização, educação, empoderamento e assessoria. 
A natureza não universal está intimamente relacionada com a centralidade do voluntariado. Das ONGs que foram examinadas ao longo do artigo, apenas a Pastoral da Criança conseguiu êxito com o voluntariado, que tinha uma condição muito especial: estar trabalhando em causa própria. As demais ações voluntárias, paradoxalmente, também parecem trabalhar em causa própria, só que como um epifenômeno da ação que se propõem. Enquanto as mães pobres trabalham na Pastoral para seus filhos, as classes médias que se mobilizam em campanhas contra a fome acabam sendo as mais beneficiadas pelo aumento da auto-estima e mesmo do exercício da cidadania. O grave é que este voluntariado, muitas vezes amador (que não é o caso da Pastoral), tem poucas condições, por melhores que sejam as intenções, de serem eficazes nas ações em que se envolvem.

A caridade, por definição, é hierárquica e autoritária, ela escolhe a quem ajudar. O próprio verbo "ajudar", presente em vários textos das ONGs examinadas, concorre para reforçar a idéia de poder. Neste pequeno número de ONGs, poder-se-ia dizer que a organização mais hierárquica, que é a Pastoral, é a mais bem-sucedida, enquanto a mais democrática, que é a "Ação da Cidadania contra A Fome", é que encontrou mais problemas em atingir seus objetivos.

A relação hierárquica, em princípio, não contribui para a inclusão, uma vez que não dá autonomia a quem se submete. Entretanto, tanto a questão da inclusão como a questão da hierarquia são complexas. Independente do grau de democracia das instituições, a distribuição de alimentos não se constitui em ação capaz de provocar processos de inclusão, salvo se acompanhada por políticas públicas, que não é o caso de ações levadas a efeito por organizações da sociedade civil. A “Ação da Cidadania contra a Fome” foi, sem dúvida, uma experiência de democracia, que pode ser pensada para outros temas, inclusive com possibilidades de provocar processos de inclusão. Mas, da forma como foi levada a efeito, proporcionou um exercício de cidadania entre os grupos incluídos, não provocando qualquer efeito de inclusão entre os grupos excluídos. De forma diversa, as ações que tinham propostas diferenciadas em relação à simples distribuição de alimentos, têm mais possibilidade de provocar inclusão, mesmo que este não seja o objetivo. Daí que se deve ter em mente dois 
problemas: a questão da hierarquia nas relações entre incluídos e excluídos, e a reprodução da exclusão independente da existência ou não da relação hierárquica.

Finalmente, a questão dos recursos aparece com grande centralidade. A eficácia da Pastoral não pode ser entendida se não for levado em conta o fato de que recebe $70 \%$ dos recursos diretamente do Estado. Isto, entretanto, não pode ser argumento para ver na sociedade civil o espaço privilegiado do autodesenvolvimento, pois a transferência de recursos é uma transferência de responsabilidade e um quebra radical na condição universal que as políticas públicas possuem.

\section{Notas}

1 “.... defini entre as prioridade de meu Governo um programa de segurança alimentar que leva o nome de "Fome Zero". Como disse em meu primeiro pronunciamento após a eleição, se, ao final do meu mandato, todos os brasileiros tiverem a possibilidade de tomar café da manhã, almoçar e jantar, terei cumprido a missão da minha vida." (Disponível em: <www.presidenciadarepublica.br>. Acesso em: 20 mar. 2004).

2 Até o governo de Fernando Collor (1990-1993), existiu no Brasil a Legião Brasileira de Assistência, órgão do governo federal que era dirigido pela primeira-dama de cada período presidencial. A chamada LBA foi um espaço privilegiado de troca de favores políticos e no último período sofreu acusações sérias de corrupção e malversação do dinheiro público. O interessante é que mesmo com o fim da LBA, não houve uma mudança significativa na postura do Estado em relação às políticas sociais. Durante os 8 anos de governo de Fernando Henrique Cardoso, as políticas sociais estiveram praticamente concentradas no programa denominado Comunidade Solidariedade, liderado pela então primeira-dama, Ruth Cardoso. Como se tratava de uma antropóloga importante no País, com trabalhos acadêmicos na área de movimentos sociais, o amadorismo do trabalho ficou, de certa forma, protegido.

3 Florini (2003) associa o aumento das organizações da sociedade civil ao aumento do número de pessoas pertencentes à classe média, no que pese esta identificação ser problemática, pois deixaria de fora da sociedade civil os movimentos populares, ela é útil como parâmetro para que se possa pensar em um corte em termos de renda e educação, abaixo do qual as pessoas não estão instumentalizadas para participarem. 
4 Diocese constitui um território sob a autoridade de um bispo. A paróquia é uma divisão da diocese, tem como autoridade o pároco e centro de suas atividades uma Igreja.

5 Por muito tempo, foi consenso na literatura de ciências sociais e história no Brasil que o país tinha apenas duas instituições organizadas, a Igreja Católica e o Exército. Atualmente, seria difícil continuar a afirmar que estas são as únicas, mas, mesmo considerando o avanço das organizações da sociedade civil, ainda deve-se considerar principalmente a presença da igreja como um elemento fundamental da organização.

6 A presença massiva das mulheres como voluntárias está aqui, muito de perto, associada ao papel de mãe destas mulheres. Todavia, deve-se chamar a atenção para o fato da existência de uma estreita relação entre o trabalho voluntário e a presença das mulheres. Enquanto estas estiveram fora do mercado de trabalho, as pertencentes às classes mais abastadas da sociedade sempre tiveram o trabalho voluntário como uma ocupação apropriada. Este, junto com as atividades filantrópicas em geral, foram formas de ocupação das mulheres. No Brasil, a filantropia, através de campanhas de arrecadação de recursos ou alimentos e roupas em caso de catástrofes naturais, sempre foi mais forte entre as mulheres do que o trabalho voluntário, como se observa em países como os Estados Unidos. Nas últimas duas décadas, em decorrência tanto do maior protagonismo da sociedade civil, como da própria ideologia neoliberal, o trabalho voluntário tornou-se uma idéia muito presente no País. Novamente, o maior contingente de voluntariado é de mulheres ou de jovens de ambos os sexos, que não conseguem entrar no mercado de trabalho.

7 Estou usando a expressão "ação pública" com o propósito de diferenciar esta da política pública, que tem como agente direto o Estado e um compromisso com "universos", mesmo quando se trata de uma política focada. A ação pública seria uma versão informal das políticas públicas e nisto está uma diferença fundamental, pois envolve questões de accountability. De certa forma, o Estado repassando recursos ao chamado Terceiro Setor, se desresponsabiliza de prestar conta de um tipo de política de que simplesmente abre mão.

8 Chandhoke (2003, p. 55), em seu aprofundado estudo sobre a sociedade civil, enfatiza um importante aspecto das organizações da sociedade civil: "The autonomy of civil society from the State emerges as an optic illusion" e, mais adiante, conclui: "civil society organization can scarlely carry out developmental work without the State provinding them with resouces and infraestructure".

9 A questão da caridade não passa por quantidade. Mesmo admitindo que a Pastoral atinja um número muito grande de pessoas, a natureza da ação continua a mesma. 
10 Trata-se da música de Aldir Blanco e João Bosco, cujo tema é o Brasil que luta contra a ditadura e que fala na luta pela "volta do irmão do Henfil".

11 A Cáritas Brasileira faz parte da Caritas Internationalis, rede da Igreja Católica de atuação social composta por 162 organizações presentes em 200 países e territórios, com sede em Roma. Organismo da CNBB (Conferência Nacional dos Bispos do Brasil), foi criada em 12 de novembro de 1956 e é reconhecida como de utilidade pública federal.

12 Segundo Luis Eduardo Soares, Betinho resolvera fundar a "Ação..." em contrapartida ao CONSEA: "decidira liderar uma campanha cívica pela cidadania e contra fome que seria uma espécie de contrapartida, na sociedade civil, do conselho" (Fico, 1999, p. 127).

13 Esta foi a única vez em que foi formada uma cadeia nacional de televisão requisitada pelo governo, para que falasse um cidadão, que não representava o Estado.

14 Herbert de Souza, assim como seus dois irmãos, era hemofílico e todos adquiriram o HIV em transfusões de sangue. A esta época seus dois outros irmãos já haviam falecido, inclusive o mais popular deles, o cartunista Henfil. Betinho apresentava-se muito debilitado fisicamente e com uma magreza radical, o que tornava mais simbólica sua luta contra a fome.

15 Um dos problemas da campanha, à época, era a grande quantidade de quilos de sal, produto de preço baixíssimo e de pouco uso, que eram levados como ingresso em espetáculos de teatro ou shows musicais que se engajavam na campanha.

16 Os críticos de Harbermas insistem na limitação de seu modelo por conta da não consideração das diferenças nos espaços públicos. Iris Young (1997; 2000) e Nancy Fraser (1997; 2003) são muito enfáticas nesta crítica, afirmando que os mais educados, com mais recursos econômicos, os brancos, os homens tem muito mais possibilidade de se fazerem ouvir do que os menos educados, pobres, negros, mulheres. Ambas propõem a construção de espaços públicos alternativos. Young propõe que cada grupo mantenha-se com suas qualidades específicas para, depois, se unirem no que chama de coalizão arco-íris. Fraser propõe o modelo dos públicos múltiplos. A experiência dos comitês da "Ação da Cidadania contra a Fome" vem ao encontro destas propostas, pois permite que grupos com afinidades e experiências comuns se reúnam espontaneamente e usem suas qualidades específicas para discutirem e resolverem problemas. Cada grupo terá seu tempo, sua forma de 
organização, sua forma de relacionamento com os outros. Não é um modelo simples, e a experiência do Ibase mostrou que a eficácia foi pequena e a duração da mobilização também.

17 O objetivo deste artigo não é fazer um survey destas organizações, mas exemplificar os diversos modelos de ONGs que começaram a existir a partir de 1993 e que têm o combate da fome como seu tema. Não existe dados sobre o número de ONGs que existem no Brasil, nem tampouco de ONGs que tratam do combate a fome. Fazer um survey sobre estas organizações é um trabalho praticamente impossível, pela inexistência de qualquer instituição a que todas estejam associadas. Além disto muitas ONGs tem vida muito curta, outras existem somente no papel, nunca tendo desenvolvido trabalho efetivo e outras ainda usam a fachada de ONGs para montarem empresas de assessoria. Edwards \& Fowler (2002) afirmam, citando dados de 1999, que nessa época existiam 210.000 ONGs no Brasil.

18 Os demais projetos são "Recicle uma Vida" (vendas de cartuchos de impressora vazios que reverte em renda para famílias que, segundo a ONG, encontram-se em risco social); Prêmio Betinho (executor do Prêmio para organizações que se destacam por seus trabalhos a favor da cidadania e contra a fome na cidade de São Paulo; este prêmio é instituído por lei municipal); Casa da Criança e do Adolescente (atende 60 crianças em idade pré-escolar); comitê para a Democratização da Informática (ensino de informática para jovens); curso de capacitação de multiplicadores de planejamento estratégico, realizado em 2000).

19 São elas: Action Aid - Índia; Bread for the World - Alemanha; Christian Aid - Reino Unido; Dutch Interchurch Aid - Holanda; Danchurch Aid Dinamarca; Diakonie - Alemanha; Comitê de Ligação de ONGs da União Européia; Society for International Development - Itália; UK Food Group - Reino Unido; World Alliance for Nutrition and Human Rights (Wanahr) - Noruega; Antenna Technologie - Suiça.

20 Nem todas as ONGs com estas características sugiram a partir de 1993; algumas existiam como associações ou grupos informais muito antes.

21 Em relação a esta ONG, é importante ressaltar que ela está associada ao Serviço Social Perseverança, fundado em 1973, que, por sua vez, faz parte do Centro Espírita Perseverança, que é mantenedora do Serviço. No site da ONG não há nenhuma referência ao Centro Espírita ou a princípios religiosos, mas é provável que esta ação de caridade seja de fundo religioso e tenha algum tipo de apoio financeiro do Centro. 
Abstract: The Brazilian society and the hunger question (19932003)

This article has as main goal to examine a set of actions of civil society organizations in Brazil, in order to deal with the question of hunger in the country. The article is divided in two parts; the first one will discuss the social question in Brazil taking into consideration two assertives: Brazil is an "economicist" country and it guarantees, constitutionally, social rights without, nevertheless, guaranteeing social policies. In the second part of the article, a set of NGOs, which have developed projects to fight hunger during the last decade of the Twentieth Century, will be examined.

Key-words: civil society, third sector, NGOs, voluntarism; social rights.

\section{Referências bibliográficas}

AÇÃO DA CIDADANIA. Disponível em: 〈www.acaodacidadania.org.br〉. Acesso em: 23 jun. 2003.

ACTION AID Brasil. Disponível em: <www.actionaid.org.br〉. Acesso em: 26 jun. 1993.

ÁGORA. Disponível em: <www.agora.org.br>. Acesso em: 26 jun. 2003.

AMIGOS DO BEM. Disponível em: <www.amigosdobem.org.br>. Acesso em: 26 jul. 2003.

ARATO, L.; COHEN, J. Civil society and political theory. Cambridge: MIT Press, 1999.

ARENDT, Hannah. A condição humana. Rio de Janeiro: Forense Universitária, 1997.

ASSOCIAÇÃO BENEFICENTE BENEDITO PACHECO (ABBP). Disponível em: <www.abbp.org.br>. Acesso em: jul. 2003.

BELIK, W; DEL FROSSI, Mauro. O Programa Fome Zero no contexto das políticas sociais no Brasil. Disponível em: 〈www.fomezero.org.br〉.

CARE Brasil. Disponível em: <www.care.org.br>. Acesso em: jul. 2003.

CÁRITAS BRASILEIRA. Disponível em: <www.caritasbrasileira.org.br〉. Acesso em: 5 maio 2003.

CENTRODEDEFESADA VIDAHERBERTDE SOUZA(CDVHS). Disponível em: <www.cdvhs.org.br>. Acesso em: 23 jul. 2003. 
CHAMBERS, Simone; KYLMICKA, W. (Ed). Alternatives conceptions of civil society. Princeton: Priceton Press, 2002.

CHANDROKE. Neera. The conceits of civil society. New Delhi: University Press, 2003.

EDWARDS, Michel. Civil society. Cambridge: Polity, 2004.

EDWARDS, Michel; FOWLER, Alan (Ed). The Earthscan reader on NGO management. London: Earthscan, 2002

FICO, Carlos. Ibase: usina de Idéias e cidadania. Rio de Janeiro: Garamond, 1999.

FLORINI, Ann. The coming democracy: new rules for running a new world. Washington: Island Press, 2003.

FOME ZERO. Disponível em: <www.fomezero.org.br>.

FRASER, Nancy. Rethinking the public sphere: a contribution to the critique of actually existing democracy. In: CALHOUN, Craig (Ed.). Habermas and the public sphere. Cambridge: MIT Press, 1996.

FRASER, Nancy; HONNETH, Alex. Redistribution or Recognition? London: Veersos, 2003.

HOWELL, Jude; PEARCE, Jenny. Civil society \& development: a critical exploration Boulder, Colo. : L. Rienner, 2001.

PASTORALDA CRIANÇA. Disponível em: <www.pastoraldacriança.org>. Acesso em: 23 set. 2003.

PINTO, Céli R J. A sociedade institucionalizada. Política e Sociedade, Florianópolis, v. 5, 2004.

PRATO CHEIO. Disponível em: <www.obj.org.br/revistaobj/noticias/ jovens_universitarios.htm>. Acesso em: 10 set. 2003.

PRESIDÊNCIA DA REPÚBLICA. Disponível em: <www.presidenciadarepublica.br>. Acesso em: 20 mar. 2004.

SOLNIT, Rebecca. Hope in the dark. New York: Nation Books, 2004.

YOUNG, Iris . Inclusion and democracy. Oxford: Oxford University Press, 2000.

YOUNG, Iris. Communication and the other: beyond deliberatice Democracy. In: BENHABIB, Seyla (Ed.). Democracy and difference (contesting the boundaries of the political). New Jersey: Princeton University Press, 1997. 